\title{
Uma identidade guerreira forjada "à base" das joelhadas e cotoveladas: as narrativas dos primeiros mestres do muay thai brasileiro
}

\author{
Ivo Lopes MÜLLER JÚNIOR* (iD) \& André Mendes CAPRARO \\ Universidade Federal do Paraná (UFPR) (Brasil)
}

Received: 09/03/2020; Accepted: 04/08/2020; Published: 08/08/2020.

ORIGINAL PAPER

\section{Resumo}

Este estudo teve como objetivo descrever as principais características do treinamento realizado no final da década de 1970 e que, posteriormente, foram base para Rudimar Fedrigo montar a academia Chute Boxe e consolidar a identidade do muay thai brasileiro. Para tanto, as seguintes questões foram elaboradas: Como eram os treinamentos ministrados por Nélio Naja nos primórdios do muay thai brasileiro, a partir da memória de alguns pioneiros desta prática. Quais as nuances do início da construção identitária do muay thai brasileiro? Na tentativa de responder a tais questionamentos recorreu-se à história oral híbrida como metodologia. Foi possível concluir que os princípios aprendidos com o grãomestre Nélio Naja, valores assentados no treinamento e em um condicionamento físico intenso, além da construção uma identidade guerreira, permitiu à academia Chute Boxe conquistar fama mundial com vitórias no MMA, forjadas "à base" de joelhadas e cotoveladas.

Palavras-chave: Desportos de combate; artes marciais; muay thai; boxe tailandês; luta.

Una identidad guerrera forjada a base de rodillazos y codazos: las narrativas de los primeros maestros del muay thai brasileño

\section{Resumen}

E, objetivo de este estudio fue describir las principales características del entrenamiento desarrollado a fines de la década de 1970 y que, posteriormente, fue la base para que Rudimar Fedrigo estableciera la academia Chute Boxe y consolidara la identidad del muay thai brasileño. Así, se elaboraron las siguientes preguntas: ¿Cómo eran los entrenamientos impartidos por Nélio Naja en los inicios del muay thai brasileño, a partir de los recuerdos de algunos pioneros de esta práctica? ¿Cuáles son los matices del comienzo de la construcción de la identidad del muay thai brasileño? En un intento de responder a estas preguntas, se utilizó una metodología basada en la historia oral híbrida. Se concluye que los principios aprendidos del gran maestro Nélio Naja, valores basados en el entrenamiento y el acondicionamiento físico intenso, además de construir una identidad guerrera, permitieron a la academia Chute Boxe alcanzar fama mundial con victorias en MMA forjadas a base de rodillazos y codazos.

Palabras clave: Deportes de combate; artes marciales; muay thai; boxeo tailandés; luchas.

\section{A warrior identity forged based on knee and elbow strikes: the narratives of the first masters of Brazilian muay thai \\ Abstract}

The present study aimed to describe the main characteristics of muay Thai training carried out in the late 1970s and that, later, was the basis for Rudimar Fedrigo to set up the Chute Boxe academy and consolidate the identity of Brazilian muay Thai. Therefore, the following questions were posed: How were the trainings given by Nélio Naja in the beginnings of Brazilian muay Thai, through the memories of some pioneers of this practice? What are the nuances of the beginning of the identity construction of Brazilian muay Thai? In an attempt to answer such questions, hybrid oral history was used as a methodology. It was possible to conclude that the principles learned from grand master Nélio Naja, values based on training and intense physical conditioning, in addition to building a warrior identity, allowed the Chute Boxe academy to achieve world fame with victories in MMA, forged based on on knees and elbows.

Keywords: Combat sports; martial arts; muay Thai; Thai Boxing; fighting.

\section{Introdução}

No mês de maio de 2016 o Ultimate Fighting Championship (UFC) desembarcou a sua estrutura itinerante na cidade de Curitiba. A edição 198 teve como luta principal o combate ente o brasileiro Fabrício Werdum e o norte americano Stipe Miotic. Segundo Camilo, Gutiérrez-García e Telles (2019), o UFC 198 gerou um impacto econômico à cidade de 12 milhões de euros. 0 evento foi realizado no Estádio Joaquim Américo Guimarães, popularmente conhecido como Arena da

${ }^{*}$ E-mail: ivojunior11@yahoo.com.br 
Baixada, e obteve um público de 45.207 pessoas. Na época foi o terceiro maior público da história do evento. Todos os ingressos foram vendidos em menos de 24 horas. Hoje, ocupa a quarta posição de maiores públicos, após a quebra do recorde no UFC 243, realizado em Melbourne, no dia 5 de outubro de 2019 com 57.127 espectadores (Ufc.com, 2019).

Uma das primeiras ações de marketing do UFC 198 foi uma chamada promocional na internet. No vídeo ${ }^{1}$ de $1 \mathrm{~min} 42 \mathrm{~s}$, a cidade é apresentada como "solo sagrado das artes marciais". Segundo matéria produzida pelo jornalista Fernando Rudinick para o jornal Gazeta do Povo, a academia Chute Boxe, liderada pelo grão-mestre Rudimar Fedrigo, tem relação direta com o termo utilizado pela organização do evento para definir a capital paranaense, pois, dos 13 combates programados para o evento, seis foram realizados por atletas que têm ou já tiveram vínculo com a academia (Rudinick, 2016). Os atletas que fizeram parte do card do UFC 198 e que já tiveram (ou ainda tinham) vínculo com a academia Chute Boxe foram: Fabrício Werdum, Anderson Silva, Cris Cyborg, Maurício Shogun, Francisco Massaranduba e Serginho Moraes. 0 atleta Anderson Silva foi cortado do evento quatro dias antes da luta por problema de saúde: precisou passar por uma cirurgia de emergência na vesícula ( $O$ Globo, 2016). A academia Chute Boxe conquistou reconhecimento mundial com vitórias no MMA, ajudando a construir a fama da cidade como a "capital brasileira da luta" e/ou "Tailândia brasileira" (Barone, 2016; Combate, 2016).

Curitiba galgou tais epítetos, pois foi um celeiro de atletas de nível nacional e internacional nas décadas de 1990 e 2000. Vários atletas brasileiros desta época, destaques no MMA internacional, foram revelados nas principais academias do Rio de Janeiro e de Curitiba. No Rio de Janeiro predominavam os atletas do jiu-jitsu, e na capital paranaense os atletas de muay thai. Em entrevista concedida ao jornalista Marcelo Barone, do Canal Combate, o atleta Maurício "Shogun" Rua informou que a cidade de "[...] Curitiba é quem mais exportou atletas. A luta está no sangue da galera, a cada esquina tem uma academia de muay thai, a galera ama, o público em geral gosta muito do esporte" (Barone,2016).

O muay thai na atualidade é considerado um esporte de combate desenvolvido a partir do processo de esportivização do Muay Boran que segundo Saengsawang et al. (2015) é a arte marcial precursora da modalidade, influenciado pela chegada do boxe inglês à Tailândia (Vail, 2014). Assim como ocorreu com o karate, o taekwondo e o judô, o muay thai se tornou uma modalidade esportiva moderna. Tanto que o muay thai integra o conjunto de modalidades que está sendo avaliado por parte do Comitê Olímpico Internacional (COI), tendo em vista a sua inclusão nos Jogos Olímpicos de 2024, a ser realizado na cidade de Paris (Zhang et al., 2018; Chitas, 2017).

Como informado anteriormente, a relação de Curitiba com o MMA remete aos primórdios da academia Chute Boxe, fundada por Rudimar Fedrigo em 1979, cujo principal referencial é o muay thai que aprendeu com o grão-mestre Nélio Borges de Souza, mais conhecido por Nélio Naja. Em entrevista ao jornalista Danilo Lavieri, Rudimar Fedrigo informou que conheceu o, então mestre, Nélio Naja aos 13 anos, considerando-o a sua principal influência no muay thai (Lavieri, 2016). Fedrigo ressalta ter sido um dos primeiros alunos na época em que Nélio Naja começou a ministrar aulas. 0 apelido usado por Nélio - "naja" - surgiu no final dos anos 1970, vindo da comparação utilizada por ele com os golpes ensinados: precisavam ser executados de forma rápida, certeira e mortífera, como o ataque da cobra naja (Lavieri, 2016). Naquele período poucos sabiam exatamente o que era o muay thai. Nesse sentido, o objetivo do presente trabalho é descrever as principais características do treinamento realizado no final da década de 1970 e que, posteriormente, foram base para Rudimar Fedrigo montar a academia Chute Boxe e consolidar a identidade do muay thai brasileiro. Para atingir o objetivo exposto, as seguintes questões foram elaboradas: Como eram os treinamentos ministrados por Nélio Naja nos primórdios do muay thai brasileiro, a partir da memória de alguns pioneiros desta prática? Quais as nuances do início da construção identitária do muay thai brasileiro?

\section{Metodologia}

$\mathrm{Na}$ tentativa de responder tais questionamentos, optou-se por utilizar os pressupostos da história oral híbrida como método de investigação. Na “[...] história oral híbrida preza-se o poder da

1 Conteúdo disponível em: https://www.youtube.com/watch?v=r-qx-m6cKOA 
'conversa', contatos ou diálogos com outros documentos, sejam iconográficos ou escritos como: historiográficos, filosóficos ou literários" (Meihy, \& Holanda, 2015, p. 129). De acordo com Alberti (2013, p. 158) existe uma inter-relação envolvendo documentos com a história oral, "[...] enquanto se obtém, das fontes já existentes, material para a pesquisa e realização de entrevista, esta última tornar-se-á novos documentos enriquecendo e muitas vezes, explicando aqueles aos quais se recorreu no início". O trabalho do historiador oral engloba uma confirmação detalhada dos fatos quando possível em outros tipos de fonte, "[...] a fim que possamos distinguir entre narrativas factualmente confiáveis, que são a maioria e os casos significativos de mitos e erro criativo" (Portelli, 2016, p. 19). Somente após uma pesquisa detalhada é possível realizar a reconstrução de um evento sem equívocos.

Este trabalho é pautado em procedimentos historiográficos, a partir da produção de fontes, valorizando o registro das narrativas de experiências dos entrevistados, proporcionando um saber relativamente novo no campo das Ciências Humanas e Sociais (Gonçalves, \& Lisboa, 2007; Ferreira, Fernandes, \& Alberti, 2000). É praticamente consenso entre os historiadores que se utilizam da oralidade, a necessidade da apropriação de dois conceitos, os de memória e identidade. Tendo em conta está máxima, foram recrutados autores como Portelli (2016), Candau (2011) e Pollak (1992).

A memória é um fenômeno construído socialmente (Pollak, 1992), podendo ser tanto individual quanto coletiva. A memória é constituída no presente, evocando o passado com a ajuda de informações tomadas de empréstimo em outras reconstruções feitas anteriormente. Ela também é um fator muito importante do sentimento de continuidade e coerência individual ou de um grupo em reconstrução de si. Ao relatar um acontecimento que seja de seu interesse ou necessidade social, a narrativa tende a ser mais acurada (Thompson, 1992), cada vez que uma memória está relativamente estabelecida, ela efetua um trabalho de conservação, de coesão, de singularidade e de continuidade (Pollak, 1992).

Assim como o conceito de memória, a definição de identidade não pode ser compreendida como algo estático. São estruturas subjetivas, representações da realidade. Existe uma interdependência entre identidade e memória. Segundo Santos (2010, p. 35):

As identidades são permanentemente reconstruídas e reinventadas. As identidades e os comportamentos que estão associados a ela são constituídos historicamente, a unidade é dada pelas relações sociais, pelo compartilhamento das perspectivas e pela crença em uma identidade comum, que redunda no sentimento de pertencimento a um grupo.

A história oral permite revelar como a constituição da memória é objeto de contínua negociação. A memória está atrelada à construção da identidade de um determinado grupo (Candau, 2011). De acordo com Pollack (1992, p. 204):

[...] a memória é um elemento constituinte do sentimento de identidade, tanto individual como coletiva, na medida em que ela é também um fator extremamente importante do sentimento de continuidade e de coerência de uma pessoa ou de um grupo em sua reconstrução de si.

O início deste estudo, pautado nos princípios da história oral hibrida, se deu a partir de um levantamento de fontes em artigos científicos, livros e jornais a respeito do início do muay thai brasileiro. Foram utilizados buscas pelos termos "muay thai", "boxe tailandês", "Nélio Naja", "UFC 198" nas plataformas: Scopus da Elsevier, Google Scholar, Google books e a Hemeroteca Digital Brasileira que faz parte da Biblioteca Nacional Digital (BNDigital) - que, por sinal, tem como missão proporcionar o amplo acesso às fontes primárias de informação histórica - cultural, científica, técnica, política, etc. Seu acervo conta com informações contidas em jornais, revistas, boletins, relatórios e outras publicações periódicas (Bettencourt, \& Pinto, 2013).

Portanto, foram utilizados neste estudo, além das fontes orais, matérias dos seguintes jornais: Correio Brasiliense (1988), Gazeta do Povo (2007; 2013; 2015; 2016); O Globo (2016); livros: Alves e Mariano (2007), Reis e Rodrigues (2018) e artigos científicos: Passos, Prado, Marchi Júnior, e Capraro (2014) e Müller Júnior e Capraro (2020). 
Neste estudo 2 foram realizadas oito entrevistas temáticas durante o ano de 2019 (Tabela 1). De acordo com Alberti (2013, p. 48) as entrevistas temáticas são adequadas para "[...] o caso de temas que têm estatuto relativamente definido na trajetória de vida dos depoentes, como um período determinado cronologicamente, uma função desempenhada ou o envolvimento e a experiência em acontecimentos". Por meio de um roteiro semiestruturado de perguntas abertas, novas questões podem ser formuladas a partir da resposta do entrevistado (Alberti, 2013). Ressalta-se que todos os entrevistados assinaram o Termo de Consentimento Livre Esclarecido e concordaram em divulgar seus nomes. A duração média das entrevistas foi de 1h28min e, após transcrição, os colaboradores receberam a devolutiva das suas respectivas entrevistas.

A escolha dos entrevistados seguiu os seguintes critérios de inclusão: 1) praticantes da modalidade que conviveram e treinaram com Nélio Naja; 2) se graduaram faixa preta; 3) fizeram parte das primeiras gerações do muay thai.

Tabela 1. Entrevistados.

\begin{tabular}{llccc}
\hline \multicolumn{1}{c}{ Grau } & \multicolumn{1}{c}{ Nome $^{3}$} & Cidade & $\begin{array}{c}\text { Faixa preta } \\
\text { (ano) }\end{array}$ & $\begin{array}{c}\text { Tempo } \\
\text { entrevista }\end{array}$ \\
\hline Grão-Mestre & "Welington Narany" Luiz da Silva & Rio de Janeiro & 1979 & $1 \mathrm{~h} 54$ \\
Mestre & Antônio "Reginaldo China" Moreira da Silva & Curitiba & 1983 & $1 \mathrm{~h} 06$ \\
Professor & Júlio Cesar "Carioca" de Souza Regueira & Curitiba / Rio de Janeiro & 1984 & $2 \mathrm{~h} 03$ \\
Grão-Mestre & "Rudimar Fedrigo" & Curitiba & 1984 & $0 \mathrm{~h}: 47$ \\
Grão-Mestre & "Fábio" Seuchi "Noguchi" & Curitiba & 1985 & $0 \mathrm{~h} 54$ \\
Grão-Mestre & "Augusto" Cesar "Cunha" & Rio de Janeiro & 1986 & $1 \mathrm{~h} 33$ \\
Grão-Mestre & "Sandro" Roberto Batista "Lustosa" & Rio de Janeiro & 1989 & $2 \mathrm{~h} 16$ \\
Grão-Mestre & "Edinei" Carlos "Pedroso" & Curitiba & 1992 & $1 \mathrm{~h} 12$ \\
\hline
\end{tabular}

Welington Narany foi o primeiro faixa preta formado por Nélio Naja em maio de 1979. Reginaldo China, treinou e ministrou aulas na academia Muaythai fundada por Nélio Naja. Júlio Cesar "Carioca "conheceu Nélio Naja na época em que ele iniciou seu trabalho com o taekwondo em Curitiba, também treinou o boxe tailandês em Curitiba e Rio de Janeiro. Rudimar Fedrigo foi o primeiro aluno a se desvincular do sistema de treinamento Nélio Naja e montar sua própria metodologia, fundando a academia Chute Boxe. Fábio Noguchi conheceu Nélio Naja no período em que ele estava regressando ao Rio de Janeiro, indo até lá realizar o exame de faixa preta, ao retornar a Curitiba, treinou e ministrou aulas na academia Chute Boxe até o início da década de 1990. "Augusto" Cunha conviveu com Nélio Naja no regresso ao Rio de Janeiro. Sandro Lustosa participou da primeira excursão carioca que foi à Curitiba junto com Welington Narany e Flávio Molina treinar e conhecer Nélio Naja em 1980. Edinei Pedroso conviveu com Nélio Naja nos últimos anos de vida, após ele regressar à Curitiba.

Após cada entrevista, foi realizada a passagem do oral para o escrito, baseada nos conceitos de Alberti (2013), denominado de "processamento", que compreende as etapas de transcrição, conferência de fidelidade da transcrição e copidesque. O copidesque objetiva ajustar o documento para facilitar a escrita do estudo e a compreensão do leitor (Alberti, 2013).

\section{Nélio Naja: o introdutor}

A história criada a respeito da origem do muay thai no Brasil é complexa e mistura em um único enredo misticismo, provações e apostas no futuro (Gazeta do Povo, 2007). A maioria dos Mestres e Grão-Mestres do muay thai brasileiro consideram Nélio (Naja) Borges de Souza como precursor da modalidade no país (Reis, \& Rodrigues, 2018). Nélio era carioca, treinou taekwondo com o Mestre Woo Jae Lee entre os anos de 1972 a 1976 (Lee, 2019). Após receber a certificação de faixa preta, mudou-se para Curitiba. Na capital do estado do Paraná “[...] iniciou ministrando aula de Taekwondo, realizou algumas adaptações e criou a sua própria versão do boxe tailandês" (Rudinick,

\footnotetext{
2 Este estudo foi homologado e aprovado pelo Comitê de Ética em Pesquisa do Instituto de Ciências Humanas da Universidade de Brasília - CEP/IH, mediante o parecer consubstanciado número 1.469.110. A inscrição do projeto junto ao Comitê Nacional de Ética em Pesquisa (CONEP) pode ser localizada no site "Plataforma Brasil" a partir do número de registro: 51225615.5 .0000 .5540

30 nome, sobrenome ou apelido em negrito, representa a forma como será referida a narrativa do entrevistado.
} 
2015; Moser, 2013). Em um primeiro momento a modalidade foi difundida com o nome de boxe tailandês (Alves, \& Mariano, 2007; Reis, \& Rodrigues, 2018).

Nélio Naja criou algumas versões a respeito de como conheceu a modalidade. Entre elas, a de maior destaque alega que teria conhecido o muay thai quando estava na aeronáutica, servindo como paraquedista. Versão confirmada pelo próprio fundador em entrevista concedida à revista digital Primeiro Round ${ }^{4}$ no ano de 2010 e contestada por alguns mestres e grão-mestres.

Segundo Müller Júnior e Capraro (2020), Nélio Naja migrou à Curitiba para ministrar aulas de taekwondo. Com poucos alunos e com a chegada do mestre Hong Soon Kang à cidade, ele passa por uma série de provações, até criar sua própria versão do boxe tailandês", conhecida como "muay thai curitibano", "muay thai brasileiro" ou "muay thai Naja". A partir da socialização com seus alunos, Nélio Naja passou a preconizar algumas ideias à respeito de como teria aprendido a modalidade. Modelou um sistema de valores e padrões de comportamento, que foi sendo transmitido de aluno para aluno e cristalizando sua versão histórica da forma como aprendeu a modalidade.

\section{3. “Uma afinidade militar”: características do treinamento}

Uma das principais características do período de inserção da modalidade no Brasil foi o treinamento baseado em práticas militares. Nélio Naja sempre teve afinidade com a militarização, seus ensinamentos eram pautados nessas práticas. 0 entrevistado Júlio Cesar "Carioca" comentou que na época do Círculo Militar5, "[...] algumas vezes treinavam na pista de cavalo, lá a gente corria, rastejava. 0 Nélio fazia uma junção do muay thai e das questões militares. A gente fazia uma corrida de maleabilidade, corria serpenteando, subia na corda".

Sandro Lustosa afirmou em sua narrativa oral que o treinamento: "[...] misturava uma espécie de educação física militarista com técnicas de taekwondo e de full contatct ${ }^{6}$. As técnicas de muay thai, para nós, eram uma grande surpresa, o objetivo era fazer danos com golpes curtos, coisas que no taekwondo não existe".

De acordo com a entrevista de "Reginaldo China", Nélio Naja gostava muito das questões militares, inclusive, com a ajuda dos alunos, pintaram a academia com as cores do exército (camuflado). Além do fato de ter prestado serviço no exército brasileiro ter aumentado a afinidade com Nélio Naja, pois conversavam com frequência a respeito das forças armadas.

Ele tinha uma afinidade com o militar, então a nossa amizade foi assim, por causa das questões militares e do treinamento que a gente fazia. Fiquei como se fosse da família, eu almoçava na casa dele, ia de lá para cá com ele. [...] E esse conhecimento que eu trazia do exército ajudava bastante. Eu fui cabo do exército no $20 \mathrm{BIB}^{7}$, e havia um entendimento entre nós. Ele queria que fizesse[mos] formações militares, tinha aquela questão do patriotismo, hino nacional, fazer acampamento. A gente fazia muita coisa diferente, coisas que as academias não têm o hábito de fazer. E o muay thai dessa época era bem diferente (entrevista de Reginaldo China, 2019).

Júlio Cesar "Carioca" comentou oralmente que quando serviu ao exército, em 1983, a maior parte do que era ensinado no batalhão, já tinha aprendido com o Nélio na academia e nos acampamentos que eram realizados na Serra do Mar (entrevista de Júlio Cesar Regueira, 2019). Rudimar Fedrigo informou que quando estava prestes a se graduar (faixa preta) teve alguns problemas ideológicos com Nélio Naja, pelo fato que ele utilizava um sistema de treinamento muito voltado ao aspecto militar, motivando a sua saída da academia Muaythai e a criação da academia Chute Boxe (entrevista de Rudimar Fedrigo, 2019).

\footnotetext{
${ }^{4}$ Disponível em https://www.youtube.com/watch?v=i6Gu45WGnHA

5 Círculo Militar do Paraná - clube social da cidade de Curitiba, fundado em 1939, que, como já estampado no nome, atende, primordialmente, às famílias de militares residentes na cidade.

${ }^{6}$ Modalidade criada nos Estados Unidos da América em 1970, englobando a parte de combate do karatê com o boxe (Pérez-Gutiérrez \& Gutiérrez-García, 2008).

720 ํㅡㄹ Batalhão de Infantaria Blindada, situado no bairro do Bacacheri em Curitiba.
} 
0 introdutor da modalidade, habitualmente, trajava roupas militares camufladas da aeronáutica e do exército brasileiro. A imagem de como uma pessoa quer ser vista ou representada "[...] constrói e apresenta aos outros e a si própria, [serve] para acreditar na sua própria representação, mas também para ser percebida da maneira como quer ser percebida pelos outros" (Pollak, 1992, p. 204). De acordo com os entrevistados, a imagem que Nélio Naja buscou retratar ao longo da vida foi a de guerreiro, pois era voltada aos preceitos militares, relacionando o treinamento às artes marciais.

Segundo Cynarski (2013) o conceito de arte marcial é definido como um método de luta, baseado na tradição das culturas guerreiras, através do treinamento e aprimoramento psicofísico, elementos espirituais, autorrealização e a autodisciplina orientadas para o progresso moral e espiritual. Seu treinamento pode ser realizado com ou sem a utilização de armas. Allsep Jr (2013) apresenta alguns elementos que são valorizados pela cultura guerreira, então, de acordo com este autor, a cultura guerreira é uma complexa combinação de atitudes e ideais sobre coisas como o heroico, a superação de sacrifícios, o espírito agressivo no combate, a compaixão com os derrotados. Além das práticas de exercícios físicos, técnicas de combate com e sem armas, Nélio Naja rotineiramente buscava inculcar em seus alunos valores, como: nunca desistir de seus objetivos; o treinamento árduo leva à perfeição; as situações difíceis são uma etapa do caminho; o lutador precisa vencer a dor e o medo para alcançar o sucesso; em combate o atleta precisa utilizar toda a eficiência técnica e de forma agressiva, em busca do nocaute; lutar pela justiça e por sua honra. Estes valores e padrões de comportamento foram repassados de aluno para aluno, cristalizando uma identidade guerreira.

Outras características apresentadas pelo muay thai criado por Nélio Naja eram as técnicas de defesa pessoal com o auxílio de armas (como bastão curto, bastão longo, tonfa ${ }^{8}$ e facas); quebramento de telhas; e a nomenclatura dos chutes ser semelhante à utilizada no taekwondo. 0 chute na coxa que veio do karate kyokushin era chamado de "irokiko" e o chute alto na cabeça era chamado de "pando". Os outros chutes eram o "yop tchagui", "dora yop tchagui", "ap tchagui", termos em coreano, país no qual veio a formação do Nélio Naja (entrevista de Reginaldo China, 2019; Fábio Noguchi, 2019; Júlio Cesar Regueira, 2019; Edinei Pedroso, 2019; Sandro Lustosa, 2019; Welington Narany, 2019; Rudimar Fedrigo, 2019; Augusto Cunha, 2019).

O Mestre Reginaldo "China" apresentou com mais detalhes o treinamento com armas ensinado por Nélio Naja aos alunos.

Treinávamos com bastão, bastão longo, bastão curto, facão... fazíamos várias coisas armados. Tinham várias situações de defesa pessoal, utilizando os cotovelos, joelhos e a movimentação. Então, existiam algumas sequências de pernas, tinha uma série de golpes que a gente chamava de tudê, que, na época, era composto por 50 golpes. Eram três sequências de chutes, duas de bastão longo e tinham outros exercícios que eram realizados com bastão curto, algumas coisas com facão, que eram passados para uma ou outra pessoa que tinha mais habilidades (entrevista de Reginaldo China, 2019).

O tudê era uma mistura de $k a t a^{9}$ com exercício de defesa pessoal composto por 50 sequências de golpes. Esses exercícios foram criados e desenvolvidos por Nélio Naja e, com o passar dos anos, deixaram de ser utilizados pelos professores da referida modalidade. Começava com uma defesa simples de soco com contragolpe, evoluía para exercícios mais complexos, como sequências de chutes, soco giratório (conhecido como "sétima"), giro de calcanhar na altura do rosto pulando e o trabalho com armas -englobando técnicas de bastão (curto e longo), faca e facão. Esse treinamento era realizado durante as aulas de muay thai ministradas, principalmente, por Nélio Naja. 0 tudê, era pré-requisito para se realizar os exames de graduação que, em um primeiro momento, eram chamados de "exames de faixas". Para conquistar a primeira graduação o aluno deveria apresentar as técnicas do 1 ao 10, para a segunda do 1 ao 20, sucessivamente até a faixa preta que era do 1 ao 50 (entrevista de Edinei Pedroso, 2019; Reginaldo China, 2019; Fábio Noguchi, 2019; Welington Narany, 2019; Sandro Lustosa, 2019; Júlio Cesar Regueira, 2019).

\footnotetext{
${ }^{8}$ Tonfa - também conhecido por bastão PR-24, bastão policial, cassetete americano.

9 Kata consiste em uma série predeterminada de movimentos que são executados com rapidez explosiva contra oponentes imaginários (Doria, Veicsteinas, Limonta, Maggioni, Aschieri, Eusebi, F., ... \& Pietrangelo, 2009).
} 
O sistema de graduação do muay thai também foi criado por Nélio Naja, sendo inspirado na cor da bandeira da Tailândia e baseado no sistema correlato do taekwondo. Fábio Noguchi ressalta que:

Dentro do taekwondo já havia as denominações de graduações, de faixas. Ele já veio com esse propósito pronto, ele já tinha essas graduações que ele havia proposto e as técnicas de defesa pessoal denominadas de tudê. Ele era muito inteligente, já tinha montado tudo dentro da cabeça dele, o que ele queria do muay thai e como ele queria executar e divulgar a modalidade (entrevista de Fábio Noguchi, 2019).

O sistema de graduação criado por Nélio Naja era, então, composto por sete graduações coloridas e mais dez dans. Iniciava na faixa branca, branca ponta vermelha, vermelha, vermelha ponta azul, azul, azul ponta preta e preta. Após a faixa preta, existiam os dans (Alves, \& Mariano, 2007). Em dezembro de 1988, o Conselho Nacional de Desportes - CND recomendou que a Confederação Brasileira de Pugilismo - CBP padronizasse as regras da modalidade, assim como o sistema de graduações, para que o boxe tailandês (muay thai) pudesse ser reconhecido como modalidade desportiva (Correio Braziliense, 1988).

A partir da normativa do CND houve a inclusão de mais duas graduações, passando de sete para nove e a exclusão dos dans para os faixas pretas. Em suma, o novo sistema de graduação do muay thai brasileiro ficou instituído da seguinte forma: (1) branca, (2) branca ponta vermelha, (3) vermelha, (4) vermelha ponta azul clara, (5) azul clara, (6) azul clara ponta azul escura, (7) azul escura, (8) azul escura ponta preta, (9) preta.

Nos primeiros exames de graduação realizados pelo introdutor da modalidade, além da parte técnica, o praticante tinha que ter um excelente condicionamento físico para realizar o exame. 0 aluno era avaliado por cada aspecto físico e técnico. Para cada graduação o praticante tinha uma quantidade mínima de exercícios a realizar, variando entre dez flexões para a primeira graduação a 100 para o exame de faixa preta. A avaliação era composta por exercícios de corrida, flexão de braço, exercícios abdominais, barra fixa, saco de pancada, o tudê e o combate propriamente dito. Vale ressaltar que no exame de faixa branca ponta vermelha era proibido deferir golpes na região da cabeça, permitindo apenas golpes no tronco e membros inferiores, comumente chamada de "sombra" pelos praticantes. Outra característica era que na faixa branca, branca ponta vermelha e na vermelha você aprendia basicamente taekwondo, com predominância de chutes. Depois da graduação vermelha ponta azul, o praticante precisava mesclar melhor as técnicas de boxe, cotovelo, clinch ${ }^{10}$ e joelhadas (entrevista de Edinei Pedroso, 2019; Reginaldo China, 2019; Fábio Noguchi, 2019; Welington Narany, 2019; Sandro Lustosa, 2019; Rudimar Fedrigo, 2019; Júlio Cesar Regueira, 2019; Passos, Prado, Marchi Júnior, e Capraro, 2014).

0 exame de faixa preta também tinha suas peculiaridades. Entre elas, apresentações de combate com bastão e facão e combate com mais de um oponente.

Quando fui fazer o exame para ponta preta não sabia que iria pegar a preta direto. Eu estava machucado, fui para o campeonato no Rio de Janeiro e quando voltei já fui fazer o exame de graduação. Eu tinha que lutar com dois pesos pesados por três rounds, fazer todo o tudê, toda a movimentação com bastão e facão. Eles sabiam, eu não sabia. Estava com a perna machucada e foi onde mais me bateram, levei seis chutes direto na perna. No último round levei uma pancada muito forte e tive que parar. Fui graduado faixa preta e continuei o trabalho (entrevista de Reginaldo China, 2019).

O sistema de graduação é uma prática comum na maioria das artes marciais e esportes de combate. Segundo Correia e Franchini (2010) os esportes de combates são práticas de lutas, artes marciais e dos sistemas de combate regulamentados por instituições esportivas. Apresentando aspectos como regras e normas regulamentadas por instituições, competição, mensuração, comparação de resultados e espetacularização. 0 processo de transição dessas graduações remete a uma ideia de tradição, parte importante da memória tanto individual quanto coletiva (Portelli,

10 Clinch: São técnicas aplicadas conta o oponente abraçado ou puxado pelo membro superior (cabeça), para que lhe sejam desferidas joelhadas tanto no tórax quanto na cabeça. 
2016). Esse processo hierárquico ajuda a motivar os participantes a estarem se esforçando ao treinamento, a criar responsabilidades e a fortalecer ainda mais a identidade de grupo, distinguindo-se perante os demais alunos menos graduados. Candau (2011, p. 122) explica que a tradição é uma peça do jogo identitário e é moldada pelo "[...] presente de onde obtém sua significação". 0 autor ainda acrescenta que o apelo à tradição encontra "[...] sua justificativa não apenas em assegurar uma continuidade fictícia ou real entre o passado e o presente, mas também em satisfazer uma lógica identificadora no interior do grupo, mobilizando deliberadamente a memória autorizada de uma tradição".

Outro elemento presente na criação da identidade da modalidade foi a definição dos primeiros uniformes, por sinal, idealizados pelo próprio Nélio Naja. Ele instituiu no início o quimono preto tipo dobok do taekwondo. Era fechado na gola, tinha o distintivo na frente, que era o pássaro garuda11, esse símbolo era em amarelo e preto, na parte de trás escrito "MUAYTHAI NAJA" com uma cobra naja no meio. Nas mangas eram bordados alguns distintivos dos alunos graduados. A calça também era preta e a faixa na cintura sobreposta à parte de cima do quimono (Imagem 1). Reginaldo China informou que "[...] esse uniforme permaneceu aproximadamente até a saída do clube Sociedade Thalia12, na academia da Carlos de Carvalho foi introduzido o agasalho de malha" (entrevista de Reginaldo China, 2019). Na academia Muaythai passou a ser instituído a calça de agasalho de malha preta e uma camiseta da mesma cor, o logotipo também mudou. Manteve-se a palavra MUAYTHAI e embaixo duas cobras najas, uma olhando para a outra com os rabos entrelaçados. Após algum tempo, começaram a treinar com calções de malha preto, bem diferente dos calções que são usados na atualidade. A faixa de graduação permaneceu na cintura sobreposta à camiseta (entrevista de Edinei Pedroso, 2019; Reginaldo China, 2019; Fábio Noguchi, 2019; Welington Narany, 2019; Sandro Lustosa, 2019; Rudimar Fedrigo, 2019; Júlio Cesar Regueira, 2019).

Imagem 1. Fotografia de 1979. Primeiros uniformes do muay thai brasileiro. Fonte: Júlio Cesar Regueira

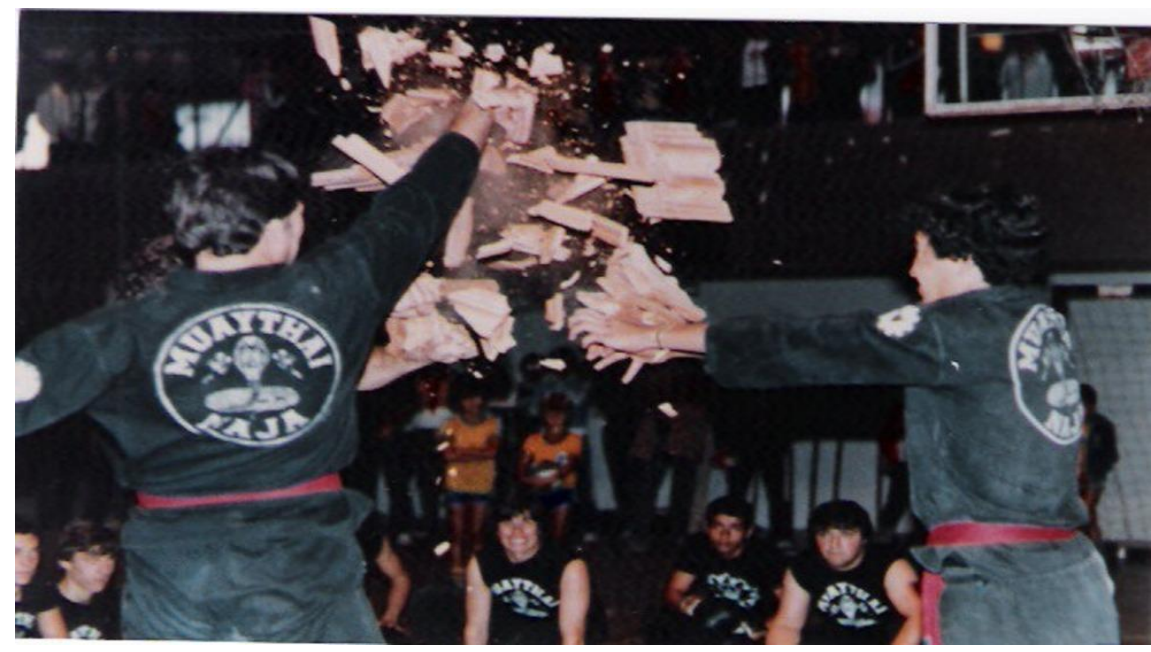

Segundo a narrativa de Fábio Noguchi, a primeira academia a "retirar" a faixa na cintura foi a Chute Boxe no ano de 1985/86, aproximadamente. Passaram a utilizar a graduação costurada na borda superior do calção. De acordo com os relatos de Sandro Lustosa, era difícil deixar de usar a faixa amarrada na cintura, pois ela representava uma hierarquia e, acima de tudo, um elemento de vaidade. De acordo com os mestres e grão-mestres pioneiros, foi no início da década de 1990 que a graduação deixou de ser utilizada no calção e foi colocada no braço.

0 desafio em abandonar o taekwondo e começar uma modalidade nova, o muay thai brasileiro, permitiu que Nélio Naja desenvolvesse a sua criatividade. Uma das maiores dificuldades na época foi encontrar material apropriado para utilizar no treinamento. Segundo a narrativa de Fabio Noguchi, reforçada por Sandro Lustosa, tudo era muito rústico. Os recursos eram escassos,

\footnotetext{
${ }^{11}$ A garuda é uma figura mitológica do hinduísmo, originariamente uma águia, um pássaro solar, brilhante como o fogo e destruidor de serpentes.
}

12 Tradicional clube social da cidade de Curitiba, com raízes étnicas alemãs, fundado em 1882. 
pois estavam começando a formar as primeiras turmas. Na academia Muaythai existiam alguns sacos de pancadas pendurados nos suportes do teto, não havia tatame, era no piso bruto. Ainda não haviam sido desenvolvidos os aparadores de chute e as luvas de foco (manoplas). Luvas de bate saco eram caras e as de boxe, além de caras, eram difíceis de encontrar. Nesta época, as luvas eram produzidas com couro natural e as partes internas eram feitas com crina de cavalo. Eram as poucas que se encontravam nas academias (entrevista de Edinei Pedroso, 2019; Fábio Noguchi, 2019; Sandro Lustosa, 2019).

Logo, a maioria dos exercícios era realizado em duplas e os golpes eram deferidos no corpo do colega. Prática conhecida como "corpo a corpo" pelos praticantes da modalidade. Utilizava-se apenas uma bandagem de farmácia para proteger as mãos. Treinavam muito nos sacos de pancadas, que eram feitos com lonas de caminhão bem espessas. Eram comuns lesões nas mãos, como cortes causados pelo impacto e atrito com o revestimento do saco de pancadas. De acordo com os entrevistados, protetor bucal era utensílio de luxo, devido à dificuldade em se encontrar (entrevista de Rudimar Fedrigo, 2019; Fábio Noguchi, 2019; Edinei Pedroso, 2019; Júlio Cesar Regueira, 2019; Sandro Lustosa, 2019; Welington Narany, 2019; Augusto Cunha, 2019). Em sua narrativa oral, Rudimar Fedrigo ressaltou o índice elevado de lesões aos praticantes, sobretudo nos exames de faixa, devido aos poucos equipamentos disponíveis.

Eles eram muito precários, por falta de equipamentos de proteção como por exemplo, protetor bucal. Realizei um exame de graduação na sociedade Thalia onde eu dava aula. E só tinham dois protetores bucais para 30 a 40 pessoas fazer o combate. Inclusive, nós colocamos dois copos com álcool, os caras lutavam e passavam o protetor bucal no álcool para o próximo utilizar. Era muito precário nessa questão de equipamentos, quase não tinham, então acidentes, como quebrar o nariz, eram mais comuns (entrevista de Rudimar Fedrigo, 2019).

De acordo com Candau (2011) e Pollak (1992), foi possível perceber que os entrevistados apresentaram uma memória coletiva, produzida no interior da classe de mestres e grão-mestres do muay thai brasileiro, a qual se alimenta de imagens, ideias, sentimentos e valores que concedem identidade e permanência a este grupo, rememorando às dificuldades encontradas no período de implantação da modalidade.

É possível notar a forma de valorização de uma identidade guerreira, por parte dos entrevistados. Apesar de todas as dificuldades, o muay thai foi capaz de superá-las e de se tornar referência nacional entre as artes marciais e esportes de combate. Hoje pois, segundo os colaboradores, no período de implantação, somente os alunos considerados guerreiros, aqueles que enfrentavam e venciam as dificuldades, permaneceram treinando com Nélio Naja. Inclusive, diferente da pratica comercial empregada na atualidade, que visa apenas os interesses do mercado (Oliveira, Lopes, Sonoda-Nunes, \& Figueiredo, 2019). Nos últimos anos as artes marciais e esportes de combate têm expandido suas opções, com o intuito de ampliar o número de praticantes, oferecendo atividades voltadas com mais ênfase à recreação, ao fitness, à aptidão física e ao wellness (Rossi, Rocha, \& Duarte, 2017).

\section{Conclusão}

Nélio Naja é considerado o introdutor do muay thai brasileiro, embora em um primeiro momento, a modalidade tenha sido difundida com o nome de boxe tailandês. De acordo com Moser (2013) o precursor da modalidade criou sua própria versão, aquela que ficou conhecida como "muay thai curitibano", "muay thai brasileiro" ou "muay thai Naja". A partir das narrativas apresentadas foi possível perceber que o método de treinamento desenvolvido por Nélio Naja, no final da década de 1970, era baseado em práticas marciais oriundas do Taekwondo, aprendidas no Rio de Janeiro com o Mestre Woo Jae Lee. 0 "muay thai Naja" tinha como principais características: técnicas de defesa pessoal com o auxílio de armas (como bastão curto, bastão longo, tonfa e facas), quebramento de telhas, técnicas de chutes elaboradas a partir do taekwondo, incrementadas com técnicas de boxe, joelhadas e cotoveladas. Os entrevistados apresentaram uma memória coletiva que, basicamente, consistia em enaltecer uma identidade guerreira, forjada por meio de um forte condicionamento físico, superando as adversidades típicas de um início sem muitos recursos. Esta identidade guerreira se constituiu a partir de valores e padrões de comportamento que Nélio Naja 
inculcou em seus alunos. Estes princípios foram repassados de aluno para aluno. Termos apresentados pelos entrevistados como "o treinamento árduo leva a perfeição", "nunca desistir", "o lutador precisa vencer a dor e o medo para alcançar o sucesso", "lutar de forma agressiva, em busca do nocaute" são utilizados até hoje por seus discípulos.

Os entrevistados também buscaram exaltar a dificuldade em se graduar no período de inserção da modalidade. Eles rememoraram que o aluno era avaliado pelos aspectos físicos e técnicos, sendo a parte de exercícios físicos composta por corrida, flexão de braço, exercícios abdominais, barra fixa, saco de pancada, o tudê e o combate propriamente dito. Nas últimas graduações os alunos que pleiteavam a graduação tinham que realizar o combate com dois ou três adversários que, na maioria das vezes, era mais experiente e pesado. Nesses exames os praticantes que almejavam a faixa preta deveriam demonstrar os valores identitários pregados por Nélio Naja em seus primeiros alunos.

Ao desvincular-se da academia Muaythai, Rudimar Fedrigo criou a academia Chute Boxe. Os princípios aprendidos com Nélio Naja, valores associados a uma identidade guerreira, permitiram à academia Chute Boxe, conquistar fama mundial com vitórias no MMA. Fama forjada "à base" de joelhadas e cotoveladas. Fama que fez com que a cidade de Curitiba fosse conhecida como o "solo sagrado das artes marciais", como apresentado no vídeo promocional do UFC 198.

Estudos relacionados ao desenvolvimento e institucionalização das artes marciais e esportes de combate são relevantes, exatamente por apontarem fatores que contribuem para o desenvolvimento destas modalidades. Ainda assim, vale ressaltar que o estudo se limitou a descrever o método de treinamento desenvolvido por Nélio Naja, no final da década de 1970 e a trajetória, em termos identitários, que a modalidade delineou até se tornar referência aos atletas de MMA. Neste sentido, sugerem-se mais estudos desta natureza, considerando outras questões que aqui não foram abordadas e que possam nortear a compreensão da história do muay thai, especialmente no Brasil.

\section{Nota dos Autores}

Este artigo foi elaborado como parte de uma investigação mais abrangente, conduzida no âmbito de Dissertação de mestrado em Educação Física do primeiro autor, apresentada à Universidade Federal do Paraná em 2020. 0 primeiro autor, deseja agradecer a todos os entrevistados pela sua prestável e valiosa colaboração.

\section{Fontes orais}

- Antônio Reginaldo “China” Moreira da Silva - Entrevista realizada em 03 de julho de 2019.

- Augusto Cesar Cunha - Entrevista realizada em 15 de setembro de 2019.

- Edinei Carlos Pedroso - Entrevista realizada em 01 de julho de 2019.

- Fábio Seuchi Noguchi - Entrevista realizada em 17 de julho de 2019.

- Júlio Cesar “Carioca” de Souza Regueira - Entrevista realizada em 29 de agosto de 2019.

- Rudimar Fedrigo - Entrevista realizada em 04 de julho de 2019.

- Sandro Roberto Batista Lustosa - Entrevista realizada em 19 de julho de 2019.

- Welington “Narany” Luiz da Silva - Entrevista realizada em 19 de agosto de 2019

\section{References}

Alberti, V. (2013). Manual de história oral. Rio de Janeiro, RJ: Editora FGV.

Allsep Jr, L. M. (2013). The myth of the warrior: Martial masculinity and the end of Don't Ask, Don't Tell. Journal of Homosexuality, 60(2), 381-400. doi: 10.1080/00918369.2013.744928

Alves, L., \& Mariano, A. (2007). Muay Thai: Boxe Thailandês. São Paulo, SP: On Line editora.

Barone, M. (2016, 10 de maio). A Tailândia é aqui: dos ídolos do Meca ao UFC, Curitiba tem vocação para luta. Combate. Recuperado de: http://sportv.globo.com/site/combate/noticia/2016/05/tailandia-e-aqui-dos-idolos-domeca-ao-ufc-curitiba-tem-vocacao-para-luta.html 
Bettencourt, A. M. M., \& Pinto, M. R. S. (2013). A hemeroteca digital brasileira. In Anais do Congresso Brasileiro de Biblioteconomia, Documentação e Ciência da Informação-FEBAB, 25(1), 10281038.

Camilo, J. A. O., Gutiérrez-García, C., \& Telles, T. C. B. (2019). Una aproximación cuantitativa al desarrollo de las artes marciales mixtas (MMA) profesionales en España y Brasil. Revista Española de Educación Física y Deportes, (426), 126-135.

Candau, J. (2011). Memória e identidade; tradução Maria Letícia Ferreira. São Paulo, SP: Contexto.

Chitas, J. P. 0. (2017). Divulgação do Muay Thai em Portugal: plano de content marketing para a rede social youtube (Tese de doutorado), Instituto Politécnico de Lisboa, Escola Superior de Comunicação Social.

Combate. (2016, 13 de maio). Especial Chute Boxe, a equipe que fez Curitiba se tornar a Tailândia brasileira. Combate. Recuperado de: http://sportv.globo.com/site/combate/noticia/2016/05/especial-chute-boxe-equipe-quefez-curitiba-se-tornar-tailandia-brasileira.html

Correia, W. R., \& Franchini, E. (2010). Produção acadêmica em lutas, artes marciais e esportes de combate. Motriz, 16(1), 1-9.

Correio Brasiliense. (1988, 16 de dezembro). CND Reconhece o Boxe Tailandês. Correio Brasiliense. P.5. http://memoria.bn.br/DocReader/docreader.aspx?bib=028274 03\&pasta=ano\%20198\&pes $\mathrm{q}=$ boxe $\% 20$ tailand $\%$ C $3 \%$ AAs

Cynarski W.J. (2013). Budo, Martial Arts and Combat Sports - Definitions, Ideas, Theories. Research Journal of Budo, 45(3), 222-241.

Doria, C., Veicsteinas, A., Limonta, E., Maggioni, M. A., Aschieri, P., Eusebi, F., ... \& Pietrangelo, T. (2009). Energetics of karate (kata and kumite techniques) in top-level athletes. European journal of applied physiology, 107(5), 603. doi: 10.1007/s00421-009-1154-y

Ferreira, M. D. M., Fernandes, T. M., \& Alberti, V. (2000). História oral: desafios para o século XXI. Rio de Janeiro, RJ: Editora Fiocruz.

Gazeta do Povo. (2007, 25 de fevereiro). Cidade foi escolhida por intuição mística. Gazeta do Povo. Recuperado de: https://www.gazetadopovo.com.br/esportes/cidade-foi-escolhida-porintuicao-mistica-adr1kmw3edrpwfusnk0wg8z0u

Gonçalves, R. D. C., \& Lisboa, T. K. (2007). Sobre o método da história oral em sua modalidade trajetórias de vida. Revista Katálysis, 10(1), 83-92.

Pérez-Gutiérrez M, Gutiérrez-García C. (2008). Estudio bibliométrico: sobre las monografías de artes marciales publicadas en España (1906-2006). Revista de Artes Marciales Asiáticas, 3(4), 22-33. doi: 10.18002/rama.v3i4.387

Lavieri, D. (2016, 12 de maio). UFC faz festa em casa. Uol esportes. Recuperado de: https://www.uol/esporte/especiais/ufc-198.htm\#ufc-faz-festa-em-casa

Lee, W. (2019). Defesa Pessoal: Hoshin-sull do taekwondo. 1.ed. - Santos, SP: Bueno Editora.

Meihy, J. C. S. B, \& Holanda, F. (2015). História oral: como fazer, como pensar. São Paulo: Contexto.

Moser, Sandro. (2013, 8 de fevereiro). MMA: de renegado a paixão nacional. Gazeta do Povo. Recuperado de: https://www.gazetadopovo.com.br/caderno-g/mma-de-renegado-a-paixaonacional-cdjtxex78byvxjyl8gw0txhqk

Müller Júnior, I. L, \& Capraro, A. M. (2020). "Ele mesmo contou isso": Nélio Naja, a produção de um mito. Movimento (ESEFID/UFRGS), 26, 26049. doi: 10.22456/1982-8918.99251

Oliveira, M. A., Lopes, J. C., Sonoda-Nunes, R. J., \& Figueiredo, A. A. A. (2019). The sportivization process of a martial art: the karate. Revista de Artes Marciales Asiáticas, 14(2s), 59-60. doi: 10.18002/rama.v14i2s.5999

Passos, D. A., Prado, R. C., Júnior, W. M., \& Capraro, A. M. (2014). As origens do "vale-tudo" na cidade de Curitiba-PR: memórias sobre identidade, masculinidade e violência. Movimento (ESEFID/UFRGS), 20(3), 1153-1173. doi: 10.22456/1982-8918.42829

Pollak, M. (1992). Memória e identidade social. Revista Estudos Históricos, 5(10), 200-215.

Portelli, A. (2016). História oral como arte da escuta. São Paulo, SP: Letra e Voz.

0 Globo. (2016, 10 de maio). Anderson Silva está fora do UFC 198, na Arena da Baixada, em Curitiba. $O$ Globo. Recuperado de: https://oglobo.globo.com/esportes/anderson-silva-estafora-do-ufc-198-na-arena-da-baixada-em-curitiba-19275963 
Reis, C., \& Rodrigues, J. A. (2018). Diamante: a história de Luiz Alves, lenda do Muay Thai e do MMA. 1.ed. - São Paulo, SP: Forma \& Conteúdo.

Rossi, L., Rocha, A., \& Duarte, J. T. S. (2017). Avaliação do estado, conhecimento nutricional e imagem corporal de lutadores de artes marciais mistas. Revista de Artes Marciales Asiáticas, 12(2), 58-65. doi: 10.18002/rama.v12i2.4794

Rudinick, F. (2015, 24 de janeiro). A vida de ermitão do mestre da luta. Gazeta do Povo. Recuperado de: $\quad$ https://www.gazetadopovo.com.br/esportes/lutas/a-vida-de-ermitao-do-mestre-daluta-ej6yq4j6x0ojt5x52fgv5332m

Rudinick, F. (2016, 31 de março). Em teaser, UFC chama Curitiba de "solo sagrado das artes marciais". Gazeta do Povo. Recuperado de: https://www.gazetadopovo.com.br/vozes/lutalivre/ufc-chama-curitiba-de-solo-sagrado-das-artes-marciais-em-teaser

Santos, M. (2010). A noção de identidade e seu uso nos estudos migratórios. Revista Interdisciplinar da Mobilidade Humana, 18(34), 27-43.

Saengsawang, P., Siladech, C., \& Laxanaphisuth, P. (2015). The history and development of Muaythai boran. Journal of Sports Science, 3(1), 148-54. doi: 10.17265/2332-7839/2015.03.007

Thompson, P. (1992). História oral: a voz do passado. Rio de Janeiro, RJ: Paz e Terra.

Ufc.com. (2019). UFC 243 Quebra recorde de público; confira o top 5. Recuperado em: https://www.ufc.com.br/news/ufc-243-quebra-recorde-de-publico-confira-o-top-5

Vail, P. (2014). Muay Thai: Inventing tradition for a national symbol. Sojourn: Journal of Social Issues in Southeast Asia, 29(3), 509-553.

Zhang, X., Tambovskij, A. N., Cherkashin, I. A., Krivoruchenko, E. V., \& Ohlopkov, P. P. (2018). Pedagogical tests for assessing the physical preparedness of the students practicing Muay Thai. Physical education of students, 22(4), 221-231. doi: 10.15561/20755279.2018.0408

\section{Author's biographical data}

Ivo Lopes Müller Júnior (Brasil). Grau preto (professor) de muay thai conquistado no ano de 2007. Graduado em Educação Física em Licenciatura Plena (2007) e Mestre (2020) em Aspectos Socioculturais do Esporte e Lazer pela Universidade Federal do Paraná - UFPR. Integrante da diretoria (Triênios 2015-2017 e 2017-2020) e arbitro da Federação Paranaense de Boxe Tailandês e MMA. Faz parte do Grupo de Estudos de Esportes de Combate, Lutas e Artes Marciais da UFPR (GESHECLAM - UFPR) tendo a modalidade em questão como objeto de estudo e do grupo de estudos em memória esportiva (História Oral). E-mail: ivojunior11@yahoo.com.br

André Mendes Capraro (Brasil). Possui graduação em Educação Física pela Universidade Federal do Paraná (1997), graduação em Psicologia pela Universidade Tuiuti do Paraná (1999), mestrado em História pela Universidade Federal do Paraná (2002) e doutorado em História pela Universidade Federal do Paraná (2007). Cursou o estágio pós-doutoral na Università Ca' Foscari di Venezia (2012-2013). Atualmente é professor Associado da Universidade Federal do Paraná. Também é professor permanente do programa de Pós-Graduação (mestrado/doutorado) em Educação Física; parecerista de revistas científicas nas áreas de Educação Física, História e Ciências Humanas; coordenador de subprojeto do Projeto Inteligência Esportiva (parceria entre Ministério do Esporte e UFPR); avaliador institucional e de cursos de graduação (INEP); e membro da International Sociology of Sport Association (ISSA) e da Società Italiana di Storia dello Sport (SISS). Tem experiência na área de Educação Física e História, com ênfase na confluência entre Humanidades e esporte. Pesquisa atualmente os seguintes temas: literatura esportiva, história das lutas, artes marciais e esportes de combate (com ênfase no mixed martial arts - MMA), história do futebol, o conceito de esporte, memória esportiva (História Oral) e o turismo esportivo, E-mail: andrecapraro@onda.com.br 